\title{
DIRECT METHOD DALAM PEMBELAJARAN BAHASA ARAB DI SMA FUTURE GATE KOTA BEKASI
}

\author{
Ade Chairil Anwar \\ Program Studi Pendidikan Bahasa Arab STAI As-Sunnah Deli Serdang \\ Jl. Medan-Tg. Morawa, Km. 13 G. Darmo, Desa B. Sari, Kec. Tg. Morawa Kab. Deli Serdang \\ satriaanhar@ymail.com
}

\begin{abstract}
Abstraksi: Direct method (metode langsung/الطريقة المباشرة) merupakan salah satu alternatif metode yang diimplementasikan dalam pembelajaran bahasa Arab di SMA Future Gate Kota Bekas. Namun, pembelajaran Bahasa Arab di sekolah tersebut belum berjalan maksimal dimana keterampilan berbahasa Arab siswa SMA belum sesuai harapan dari stakeholder sekolah tersebut. Oleh karena itu, pelitian ini bertujuan untuk mengetahui alasan rasional digunakannya direct method dalam pembelajaran Bahasa Arab di SMA Future Gate Kota Bekasi, model implementasi direct method dalam pembelajaran Bahasa Arab di SMA Future Gate Kota Bekasi tersebut, dan problematika dan bagaimana sekolah menyelesaikan problematika pembelajaran bahasa Arab tersebut.
\end{abstract}

Kata Kunci : Direct Method, Bahasa Arab, dan SMA Future Gate.

\section{Pendahuluan}

Metode pembelajaran adalah seperangkat kegiatan (activity), tugas (task), pengalaman belajar (learning experience) yang digunakan guru dalam proses pembelajaran dalam lingkungan belajar. ${ }^{1}$ Definisi tersebut menunjukkan bahwa sebuah metode pembelajaran harus meliputi kegiatan, tugas, dan pengalaman yang diperoleh siswa dalam pembelajaran, karena metode merupakan salah satu aspek penting dalam menunjang keberhasilan pembelajaran, ia terdiri dari seperangkat prosedur atau langkah-langkah kegiatan yang dilakukan oleh guru sehingga memberikan pengaruh (impact) kepada peserta didik dalam bentuk penguasaan terhadap pengetahuan (knowledge), keterampilan (skill), dan sikap (attitude).

Penerapan metode atau prosedur-prosedur di atas bukan berarti bahwa guru harus terpaku pada satu kegiatan beserta prosedurnya, tetapi guru dituntut untuk kreatif dalam menerapkan berbagai kegiatan dan prosedur dalam membelajarkan materi tersebut. Dalam arti, bahwa guru dituntut menguasai berbagai metode (kegiatan, langkah-langkah pembelajaran) dan dapat menerapkannya dengan

${ }^{1}$ J.C. Richard, The Language Teaching Matrix, (Cambridge: Cambridge University Press, 1990), hlm. 35 . 
baik. ${ }^{2}$ Dikarenakan sebuah metode bersifat relatif dan tentatif sesuai dengan kemampuan guru dalam mengidentifikasi bakat dan karakteristik peserta didik. Termasuk dalam pembelajaran bahasa kedua (asing), di antaranya pembelajaran bahasa Arab.

Salah satu metode pembelajaran bahasa adalah direct method (metode langsung/(الطريقة المبانشر). Metode ini merupakan salah satu alternatif metode yang diimplementasikan dalam pembelajaran bahasa Arab. Terlepas dari metode tersebut memiliki keunggulan dan kelemahan. Namun, secara praksis metode tersebut telah menjadi pilihan dalam pembelajaran bahasa Arab di Sekolah/Madrasah di setiap jenjang pendidikan (dasar, menengah, dan tinggi). Implementasi itu didasarkan pada tujuan pembelajaran yang ingin dicapai dalam pembelajaran bahasa Arab tersebut.

Salah satu lembaga pendidikan yang menggunakan direct method adalah SMA Future Gate Kota Bekasi. Pembelajaran Bahasa Arab tersebut diindikasikan dengan diwajibkannya Guru dan Murid untuk selalu menggunakan Bahasa Arab dalam Kegiatan Belajar Mengajar (KBM) serta sebisa mungkin dihindari penggunaan bahasa Indonesia (bahasa formal) dalam pembelajaran Bahasa Arab tersebut. $^{3}$

Namun demikian, pembelajaran Bahasa Arab di sekolah tersebut belum berjalan maksimal dimana keterampilan berbahasa Arab siswa SMA belum sesuai harapan dari stakeholder sekolah, ketidakmaksimalan tersebut diindikasikan dengan belum terciptanya lingkungan bahasa (language environment/بيئة اللغوية) di lingkungan sekolah yang merupakan cita-cita dan sesuai dengan visi-misi sekolah. $^{4}$

Berpijak dari kegelisahan tersebut, maka diperlukan penelitian lebih lanjut guna mengkaji lebih jauh tentang alasan rasional digunakannya direct method dalam pembelajaran Bahasa Arab di SMA Future Gate Kota Bekasi, Bagaimana model implementasi direct method dalam pembelajaran Bahasa Arab di SMA

\footnotetext{
${ }^{2}$ Sembodo Ardi Widodo, Model-model Pembelajaran Bahasa Arab, dalam Jurnal Al'Arabiyah No. 2 Vol. 2, Januari 2006, hlm. 3.

${ }^{3}$ Berdasarkan pre-eliminary Research di Sekolah tersebut serta wawancara dengan Kepala SMAIT Future Gateyaitu Ust. Aniq tanggal 5 Desember 2015.

${ }^{4}$ Idem.
} 
Future Gate Kota Bekasi tersebut, serta apa problematika dan bagaimana sekolah menyelesaikan problematika pembelajaran bahasa Arab tersebut. Penelitian ini diharapkan dapat memberikan signifikansi dan kontribusi dalam khazanah keilmuan (significance and contribution to knowledge) dalam metode pembelajaran bahasa.

\section{Pembahasan}

\section{Direct Method}

Secara historis, direct method ini lahir sebagai reaksi terhadap penggunaan grammar-translation method yang mengajarkan bahasa seperti bahasa yang mati. Dimana sejak tahun 1850 telah muncul wacana yang ingin menjadikan pembelajaran bahasa asing lebih hidup, menyenangkan, dan efektif. Wacana tersebut menuntut adanya perubahan yang mendasar dalam metode pembelajaran bahasa asing.Inilah yang kemudian melahirkan metode baru dalam pembelajaran bahasa asing, yang dinamakan dengan metode langsung (direct method).

Menjelang abad ke-20 direct method cukup dikenal dan dipraktekkan secara masif dalam pembelajaran bahasa asing. Asumsi dasar dari direct method adalah mirip dengan metode seri gouin, yaitu belajar bahasa kedua sama seperti belajar bahasa pertama dengan lebih menekankan pada interaksi lisan, penggunaan spontan dari bahasa target, tidak ada terjemahan antara bahasa pertama dan kedua, dan tidak ada aturan tata bahasa. ${ }^{5}$

Metode ini sampai sekarang masih banyak digunakan dalam pembelajaran bahasa asing termasuk bahasa Arab, sebut saja misalnya di Indonesia ada Pondok Modern Darussalam Gontor (PMDG). Pondok tersebut menggunakan direct method dalam pembelajaran bahasa Arab dan bahasa Inggris. Karena sejak berdirinya, menekankan pada kemampuan komunikasi langsung dengan kedua bahasa asing tersebut, sehingga guru bahasa asing tidak boleh menggunakan sistem terjemahan. Di samping itu, pembelajaran asing dilengkapi alat atau media berupa alat peraga, gambar, di samping laboratorium bahasa. ${ }^{6}$

${ }^{5}$ H. Douglas Brown, Teaching by Principles: An Interactive Approach to Language Pedagogy, (San Francisco: San Francisco State University, 1994), hlm. 9-10.

${ }^{6}$ Lebih lanjut lihat Abdullah Syukri Zarkasyi, Manajemen Pesantren; Pengalaman Pondok Modern Gontor, (Ponorogo: Trimurti Press, 2005), hlm. 144-156. 
Telah banyak literatur yang membahas tentang direct method, termasuk definisinya, baik secara eksplisit maupun implisit. Berikut adalah beberapa definisi direct method yang dikemukakan oleh para pakar;

"Direct Method adalah metode yang menekankan pada menyimak dan berbicara. Kegiatan belajar bahasa dalam metode langsung menekankan pada hubungan antara kata dan frase dengan benda atau dalam bentuk tindakan nyata, tanpa menggunakan bahasa pertama siswa sama sekali. Keterampilan komunikasi lisan ini dikembangkan melalui tahapan yang dirancang secara seksama yang dilakukan dengan menggunakan kegiatan tanya jawab antara guru dan siswa dalam kelas kecil secara intensif. Tatabahasa diajarkan secara induktif melalui kalimat-kalimat yang diucapkan guru kepada siswa, sehingga lama-lama siswa bisa menyimpulkan sendiri bagaimana kalimat yang benar, dan materi yang baru selalu diperkenalkan pertama kali secara lisan". 7

"Direct method yang terkadang dinamakan juga sebagai natural method (metode alamiah) dikarenakan kebergantungannya pada bahasa lisan dalam proses pembelajaran bahasa asing dan menghindari bahasa Ibu dalam proses pembelajarannya serta mengkontekstualisasikan kalimatkalimat laiknya penutur bahasa asli. Meskipun jauh dari unsur-unsur alamiah dikarenakan kata-kata dan kalimat yang disampaikan pada peserta didik juga digunakan sebagai contoh dalam penyusunan kalimat shorfiyah (morfologi) dan nahwiyah (sintaksis) yang akan dipelajarinya. Kondisi tersebut, sangat tidak mungkin jika dilihat dari perspektif ilmiah, khususnya dalam tahap pertama, dimana bahasa Ibu sama sekali tidak digunakan. Padahal secara teoretis dibutuhkan bahasa ibu untuk menjelaskan kaidahkaidah itu". 8

"Metode ini disebut juga direct method karena selama pelajaran guru langsung menggunakan bahasa asing yang diajarkan, sedangkan bahasa murid tidak boleh digunakan. Untuk menjelaskan arti suatu kata atau kalimat digunakan gambar-gambar atau peragaan". 9

Dari batasan-batasan dari definisi di atas, penekanan para pakar tersebut cukup beragam namun memiliki kesamaan secara substansial, yaitu menginginkan adanya kontekstualisasi dari kata atau kalimat yang dipelajari dan menghindari penggunaan bahasa ibu dalam pembelajaran bahasa asing serta menuntut adanya penggunaan media pembelajaran yang dapat menunjang kemampuan berbicara

7 A. Syukur Ghazali, Pembelajaran Keterampilan Berbahasa; Dengan Pendekatan Komunikatif-Interaktif, (Bandung: Aditama, 2010), hlm. 94.

${ }^{8}$ Naif Harama \& Ali Hajaja, Al-Lughah al-Ajanabiyat, Ta'lîmuhâ wa Ta'allumuhâ, (Kuwait: 'Alam al-Ma'rifah, 1988), hlm. 159-160.

${ }^{9}$ Muljanto Sumardi, Pengajaran Bahasa Asing; Sebuah Tinjauan Dari Segi Metodologi, (Jakarta: Bulan Bintang, 1974), hlm. 33. 
pada peserta didik, karena ia diharapkan dapat berkomunikasi dengan bahasa target dengan baik.

Dengan demikian, dapat dikatakan bahwa direct method adalah sebuah metodologi pembelajaran bahasa asing yang menggunakan bahasa target dalam menyajikan materi pembelajarannnya. Baik dalam kegiatan awal (opening), pembentukan kompetensi atau materi utama (main activity), dan kegiatan akhir atau penutup (closing). Untuk menjelaskan materi pembelajaran (subject matter), guru dapat menggunakan alat atau media peraga berupa untuk mendemonstrasikan dan menggambarkan materi pembelajaran tersebut.

Dalam konteks pembelajaran bahasa Arab bagi penutur non-Arab, maka prinsip-prinsip direct method tersebut memiliki fokus dan penekanan pada tujuantujuan pembelajaran sebagai berikut:

1. Penguasaan dan pengembangan bahasa secara komunikatif yang berakar dalam hubungan langsung antara pengalaman dan ekspresi. Oleh karena itu, bahasa lisan lebih diutamakan (مهارة الكلام), sedangkan membaca dan mengarang diberikan kemudian.

2. Untuk menjaga hubungan langsung antara pengalaman dan ekspresi. Maka pemakaian bahasa lain sebagai perantara tidak boleh dilakukan. Dengan kata lain, pembelajaran menggunakan bahasa Arab secara total.

3. Pembelajaran diberikan sesuai dengan garis yang dilalui oleh suatu pembelajaran dalam belajar bahasa ibunya, artinya pembelajaran bahasa Arab diibaratkan belajar bahasa pertama atau bahasa ibu, dengan demikian siswa akan lebih termotivasi untuk lebih serius dengan materi yang tengah diajarkan.

4. Penguasaan struktur tatabahasa (النحو) dan pemakaian bahasa (الصرف) diajarkan secara induktif, sebab jika diajarkan secara deduktif, maka dikhawatirkan siswa tidak akan menguasai kemahiran berbahasa secara komunikatif, karena ia takut untuk berbicara dalam bahasa Arab ketika harus terpaku dengan struktur gramatikal.

5. Waktu lebih banyak digunakan untuk latihan-latihan berbahasa secara lisan ( dan lain-lain), sehingga siswa terbiasa menggunakan pelbagai kata dan kalimat secara nyata dalam pergaulan sehari-hari tanpa dihantui rasa takut untuk berbahasa Arab secara aktif. 
Karakteristik tersebut pada perkembangan selanjutnya akan memberikan dampak positif dalam pemerolehan bahasa kedua, khususnya bahasa Arab. Dampak positif tersebut antara lain:

1. Makna sebuah kata atau kalimat bahasa Arab akan mudah difahami secara jelas karena melalui penyajian objek secara fisik seperti gambar, dan lain-lain.

2. Koreksi lebih ditekankan kepada siswa bukan pada guru, sehingga memudahkan siswa untuk berfikir tentang target bahasa,

3. Guru memberikan kesempatan lebih kepada siswa untuk menggunakan kosa kata atau kalimat dalam pelbagai konteks, sehingga lebih efektif dan faktual sesuai dengan kebutuhan komunikasi siswa,

4. Interaksi yang terjadi antara siswa dengan guru, dan siswa dengan siswa akan mudah dilakukan, mengingat mereka termotivasi untuk berkomunikasi secara langsung menggunakan bahasa target, dan

5. Siswa dapat terbentuk untuk berfikir dalam mencapai kemahiran berbahasa Arab.

Adapun keunggulan dan kelemahan dari direct method adalah sebagai berikut;

\section{Keunggulan}

a. Direct method memprioritaskan pada kemampuan berbicarta dari pada kemampuan membaca, menulis, dan terjemah dengan asumsi bahwa bahasa itu adalah berbicara,

b. Menghindari sistem penerjemahan dan menganggap hal itu tidak begitu memberikan dampak dalam pembelajaran bahasa asing dan hanya akan memberikan kerancuan dalam pencapaian tujuan pembelajaran bahasa,

c. Tidak memberikan ruang bagi bahasa Ibu (untuk digunakan) dalam pembelajaran bahasa asing,

d. Menghubungkan langsung antara materi (subject matter) yang tengah dipelajari dengan konteks dari kalimat tersebut,

e. Tidak menggunakan kaidah-kaidah nahwu, karena dipandang tidak begitu memberikan dampak positif dalam memperoleh kemampuan bebahasa, dan 
f. Menggunakan sistem pengulangan dan menghafal yang senantiasa memperlihatkan kalimat-kalimat bahasa asing yang begitu banyak kepada peserta didik. $^{10}$

\section{Kelemahan}

a. Cenderung menekankan pada penguasaan kemahiran berbahasa secara lisan dan mengabaikan struktur gramatikal (قو اعد اللغة العربية),

b. Mensyaratkan adanya guru yang memiliki kualitas yang mumpuni atau menguasai kemahiran berbahasa terutama lisan (مهارة الكلام),

c. Dibutuhkan pelbagai media pembelajaran (alat peraga, gambar, dan lainlain),

d. Tidak mentoleransi adanya keberagaman kompetensi siswa,

e. Tidak bisa dilakukan dalam waktu yang terbatas, dan

f. Sulit jika diimplementasikan dalam kelas besar.

Selanjutnya berikut adalah Model-Model Penyajian Materi dalam direct method;

1. Reading Aloud (membaca nyaring),

2. Question and Answer Exercise (latihan tanya jawab),

3. Getting Students to Self-Correct (siswa mengoreksi diri sendiri),

4. Conversation Practice (mempraktekkan percakapan),

5. Fill in the blank exercise (latihan isian),

6. Dictation (dikte),

7. Map Drawing (menggambar peta), dan

8. Paragraph Writing (menulis paragraf). ${ }^{11}$

\section{Alasan Rasional Implementasi Direct Method}

SMA Future Gate merupakan sekolah yang menekankan perpaduan antara ilmu pengetahuan, keimanan dan ketakwaan, serta akhlak mulia, SMA Future Gate didukung oleh tenaga pendidik yang berpengalaman dan memiliki latar belakang sesuai dengan karakter serta bidang pembelajaran yang menjadi

\footnotetext{
${ }^{10}$ Idem.

${ }^{11}$ Dianne Larsen-Freeman, Techniques and Principles ..., (Oxford: Oxford University Press, 2003), hlm. 30-32.
} 
tanggung jawab dalam membangun, mengembangkan, dan membina kepribadian, kemampuan, serta kecerdasan siswa yang didukung oleh pengembangan kurikulum yang tepat.

Pengembangan Kurikulum yang inovatif, progresif, dan visioner adalah ciri khusus sekolah yang dikembangkan di SMA Future Gate. Kurikulum SMA Future Gate didesain untuk menyambut peluang-tantangan masa depan. Jenjang SMA merupakan tangga terakhir menuju pendidikan tinggi. Penting sekali bagi siswa SMA untuk memiliki kesiapan berupa penguasaan basis dan instrumen belajar, mencakup basis aqidah, karakter, pemahaman Alquran dan Sunnah. Mencakup pula instrumen bahasa dan learning skill. ${ }^{12}$

Sebagai sekolah yang berbasiskan Islam, SMA Future Gate memberikan perhatian khusus terhadap mata pelajaran yang menunjang pada pemahaman keislaman yang kaffah, salah satunya penguasaan bahasa Arab bagi para siswanya. Penguasaan bahasa Arab ini penting mengingat target utama dari proses pendidikan di SMA Future Gate adalah bagaimana anak mampu lolos seleksi ke kampus-kampus yang menjadikan bahasa Arab sebagai pengantar seperti LIPIA Jakarta maupun kampus-kampus lainnya. ${ }^{13}$

Bahkan, menurut pengakuan guru bahasa Arab di sekolah tersebut disebutkan bahwa siswa-siswa lulusan SMA Future Gate diharapkan dapat melanjutkan studi ke Universitas-universitas di Timur Tengah seperti Universitas Al-Azhar Mesir dan Universitas Islam Madinah. ${ }^{14}$

Guna mengejawantahkan idealisme tersebut, sekolah berupaya melakukan langkah-langkah progresif dengan cara merekrut SDM-SDM yang memiliki kapasitas keilmuan yang mumpuni, menyediakan fasilitas yang mencukupi seperti; kelas yang representatif, penyediaan buku berbahasa Arab untuk pembelajaran maupun perpustakaan, dan alat atau media pembelajaran yang berbasis teknologi informasi yang dapat digunakan oleh semua orang yang terlibat

12 Profil SMA Future Gate Tahun 2016.

${ }^{13}$ Berdasarkan hasil wawancara dengan guru bahasa Arab SMA Future Gate yaitu Ust. Khusna Fakhrudin, S.Pd.I dan Ust. Kukuh Prasetyo, S.Pd.I pada tanggal 26 dan 27 September 2016.

${ }^{14}$ Idem. 
dalam pembelajaran bahasa Arab. ${ }^{15}$

Adapun buku yang digunakan dalam pembelajaran bahasa Arab di SMA Future Gate antara lain adalah; العربية للناشئين dan. Bروس اللغة العربية. Buku tersebut dipilih dikarenakan beberapa alasan, antara lain sebagai berikut;

1. Buku tersebut lazim digunakan oleh lembaga-lembaga pendidikan berbasis bahasa Arab seperti LIPIA Jakarta, Ma'had-ma'had di bawah supervisi atau berafiliasi ke LIPIA dan Timur Tengah, atau kampus-kampus Timur Tengah itu sendiri.

2. Buku tersebut lazim digunakan bagi pembelajar bahasa Arab yang bukan penutur asli bahasa Arab seperti Pondok Modern Gontor Ponorogo (PMDG) dan lain sebagainya. Dengan begitu, guru (atau di SMA Future Gate lebih sering menggunakan panggilan Ustadz) bahasa Arab yang rerata merupakan alumni pondok atau ma'had sudah familiar atau tak asing lagi ketika harus mengajar bahasa Arab dengan menggunakan buku tersebut.

3. Dari sisi content (isi/materi), buku tersebut menggunakan bahasa Arab, hal ini diharapkan dapat memberikan motivasi kepada siswa agar selalu berusaha untuk dapat memahami teks bahasa Arab secara langsung, sehingga suasana pembelajaran menjadi lebih hidup, lebih 'arab', karena semua orang yang terlibat dalam pembelajaran berusaha meningkatkan kemampuan bahasa Arabnya. ${ }^{16}$

Dengan alasan itu pula, setiap guru bahasa Arab - terutama kelas bahasamemilih metode pembelajaran bahasa yang sesuai dengan kedua buku tersebut, meskipun ada modul yang juga dijadikan rujukan atau pijakan dalam proses pembelajaran bahasa Arab di sekolah tersebut. Metode yang digunakan dalam pembelajaran bahasa Arab di SMA Future Gate adalah metode langsung (direct method) atau dalam bahasa Arab disebut dengan الطريقة المباشرة.

Sebagai metode yang menekankan pada kemahiran menyimak (مهارةالإستماع) dan kemahiran berbicara (مهارة الكلام). Direct method menjadi pilihan yang tepat

\footnotetext{
${ }^{15}$ Berdasarkan hasil wawancara dengan Kepala Sekolah yaitu Ust. Abdul Rohim, S.Pd tanggal 24 September 2016.

${ }^{16}$ Berdasarkan hasil wawancara dengan guru bahasa Arab SMA Future Gate yaitu Ust. Khusna Fakhrudin, S.Pd.I dan Ust. Kukuh Prasetyo, S.Pd.I pada tanggal 26 dan 27 September 2016.
} 
bagi guru yang mengharapkan siswanya dapat berkomunikasi lisan maupun tulisan dalam berbahasa asing, sebab dengan metode tersebut, pembelajaran dilaksanakan secara eksklusif dalam bahasa target, lebih mengutamakan praktek, materi yang berkaitan dengan tata bahasa hanya diajarkan secara induktif.

Selanjutnya, berikut alasan utama dipilihnya direct method dalam pembelajaran bahasa Arab di SMA Future Gate Kota Bekasi;

1. Tujuan akhir dari proses pendidikan di SMA Future Gate adalah siswa dapat melanjutkan studi ke LIPIA dan Timur Tengah, sehingga sedini mungkin siswa dibiasakan untuk menerima materi dalam bentuk bahasa Arab terutama dalam pembelajaran bahasa Arab.

2. Siswa SMA Future Gate sejak awal (semester 1 dan 2) sudah dibekali dengan kemampuan dasar bahasa Arab, sehingga direct method berfungsi untuk memberikan rangsangan (stimulation), penguatan (reinforcement), dan pengulangan (repetition) terhadap materi-materi yang telah diajarkan sebelumnya.

3. Guru-guru yang mengampu mata pelajaran bahasa Arab di SMA Future Gate memiliki kemampuan bahasa Arab yang mumpuni, semuanya pernah mengenyam pendidikan di LIPIA Jakarta, sehingga penggunaan direct method dalam pembelajaran bahasa Arab dapat dilaksanakan karena guru menguasai bahasa Arab laiknya bahasa Ibu.

4. Bahan ajar yang berupa buku bahasa Arab (العربية للنانشئن dan دروس اللغة العربية) yang dipakai oleh guru sebagian besar menggunakan bahasa Arab (Kelas IPA dan IPS) dan bahkan seluruhnya menggunakan bahasa Arab (Kelas Bahasa), sehingga mau tidak mau bahasa Arab menjadi bahasa pengantar, bahasa utama, dan bahasa penutup dalam pembelajaran.

5. Tujuan lain dari pembelajaran bahasa Arab di SMA Future Gate adalah terbinanya siswa yang memiliki keimanan, ketaqwaan, dan kafāah syar'iŷah yang sesuai dengan Alquran dan Sunnah, sehingga untuk itu dibutuhkan modal dasar berupa bahasa Arab agar siswa mampu mengkaji ilmu agama dari sumber aslinya yaitu bahasa Arab baik kitab-kitab Tafsir maupun kitab-kitab 
hadis, dan kitab-kitab lainnya yang menunjang penelaahan ilmu agama (Islam) tersebut. $^{17}$

\section{Model Pembelajaran Bahasa Arab Berbasis Direct Method}

Kemampuan berbahasa Arab serta sikap positif terhadap bahasa Arab tersebut sanagt penting dalam membantu sumber ajaran Islam yaitu Alquran dan Sunnah, serta kitab-kitab berbahasa Arab yang berkenaan dengan Islam bagi siswa. Untuk itu, pembelajaran bahasa Arab perlu dipersiapkan dengan matang, pembelajaran bahasa Arab mencakup empat keterampilan berbahasa yang diajarkan secara integral mulai dari menyimak (استماع/listening) dan berbicara (كلام/Speaking), menulis (كتابة/writing) dan membaca ( $\left(\dot{\circ}_{\&} /\right.$ /reading).

Sebagai sekolah yang mengajarkan bahasa Arab untuk semua jenjang dan jurusan serta mengharapkan siswa memiliki kemampuan reseptif sekaligus kemampuan produktif dimana siswa diharapkan dapat berkomunikasi dalam bahasa Arab dan memahami teks yang berbahasa Arab. Maka guna mendukung keberhasilan pembelajaran bahasa Arab, SMA Future Gate sejak awal berkomitmen untuk menggunakan direct method dalam pembelajaran bahasa Arab untuk semua kelas dan jenjang tersebut.

Komitemen tersebut didukung oleh tersedianya buku-buku ajar yang berbahasa Arab seperti العربية للناشئين dan دروس اللغة العربية, dan buku-buku bahasa Arab lainnya. Selain itu, buku-buku penunjang yang tersedia di perpustkaan sekolah pun banyak yang berhasasa Arab, sehingga implementasi direct method merupakan sesuatu yang bersifat aksiomatik bagi guru dalam mengajar bahasa Arab di kelas.

Adapun warkat pembelajaran yang disusun oleh guru bahasa Arab di SMA Future Gate guna mempermudah dan mengakselesasi pencapaian target pembelajaran dan ketertiban administrasi pemebelajaran, semua guru bahasa Arab baik yang mengajar di kelas X, Kelas XI (IPA, IPS, dan Bahasa), dan Kelas XII (IPA, IPS, dan Bahasa) diwajibkan untuk menyusun warkat-warkat yang berbasis kedua buku daras di atas, berikut adalah warkat-warkat yang wajib disusun guru bahasa Arab di SMA Future Gate antara lain adalah; 1) Modul Pembelajaran, 2)

17 Berdasarkan kesimpulan dari dokumentasi profil sekolah dan wawancara dengan stakeholders SMA Future Gate Kota Bekasi antara tanggal 26 sampai dengan 30 September 2016. 
Silabus Pembelajaran, dan 3) Rencana Pelaksanaan Pembelajaran (RPP).

Berdasarkan hasil dokumentasi dan observasi terhadap kegiatan pemebelajaran bahasa Arab di sekolah tersebut, dapat disimpulkan bahwa pembelajaran bahasa Arab di SMA Future Gate Kota Bekasi memiliki banyak kesamaan dengan metode langsung atau (direct method/الطريقة المباشرث). Kesamaan tersebut dapat dilihat dari aspek-aspek berikut ini; 1) Prinsip-prinsip Pembelajaran Berbasis Direct Method, 2) Karakteristik Pembelajaran Berbasis Direct Method, dan 3) Model-Model Penyajian Materi Berbasis Direct Method. Selengkapnya mengenai kesamaan prinsip, karakterisktik, dan model penyajian materi tersebut adalah sebagai berikut;

1. Perbandingan Kualitatif Antara Prinsip Direct Method dengan Pembelajaran Bahasa Arab di SMA Future Gate Kota Bekasi

\begin{tabular}{|c|c|c|}
\hline No. & Prinsip Direct Method & $\begin{array}{l}\text { Pembelajaran Bahasa Arab di SMA } \\
\text { Future Gate }\end{array}$ \\
\hline 1. & $\begin{array}{l}\text { Pembelajaran } \\
\text { dilaksanakan secara } \\
\text { eksklusif dalam bahasa } \\
\text { target }\end{array}$ & $\begin{array}{l}\text { Selama proses pembelajaran berlangsung, } \\
\text { Guru dan murid menggunakan bahasa } \\
\text { Arab secara langsung, dan hanya beberapa } \\
\text { kata saja Nampak Guru menggunakan } \\
\text { bahasa Indonesia. }\end{array}$ \\
\hline 2. & $\begin{array}{lr}\text { Kata dan kalimat yang } \\
\text { memiliki hubungan } \\
\text { dengan } & \text { aktivitas } \\
\text { sehari-hari } & \text { saja yang } \\
\text { menjadi } & \text { fokus } \\
\text { pembelajaran } & \end{array}$ & $\begin{array}{l}\text { Kata dan kalimat yang berkaitan dengan } \\
\text { materi pokok selalu diulang-ulang dan } \\
\text { diterjemahkan ke dalam bahasa Indonesia, } \\
\text { misal ketika materi yang diajarkan } \\
\text { berkaitan dengan sekolah (مدرسة), maka kata } \\
\text { yang berkaitan dengan sekolah terus } \\
\text { diulang dan diterjemahkan seperti; الفصل المعمل, المكتبة }\end{array}$ \\
\hline 3. & $\begin{array}{lr}\text { Kelas } & \text { lebih } \\
\text { menekankan } & \text { pada } \\
\text { keterampilan } & \\
\text { komunikasi } & \text { berupa } \\
\text { tanya-jawab } & \text { antara } \\
\text { guru dan siswa } & \end{array}$ & $\begin{array}{l}\text { Kegiatan Tanya jawab antara guru-murid } \\
\text { maupun murid-murid merupakan kegiatan } \\
\text { yang dominan dalam pembelajaran bahasa } \\
\text { Arab, setiap siswa secara berpasangan } \\
\text { melakukan dialog seperti contoh di bawah } \\
\text { ini; } \\
\text { Siswa A; من أين أنت قادم؟ } \\
\text { Siswa B; من المبع }\end{array}$ \\
\hline
\end{tabular}




\begin{tabular}{|c|c|c|}
\hline 4. & $\begin{array}{l}\text { Tata bahasa diajarkan } \\
\text { secara induktif }\end{array}$ & $\begin{array}{l}\text { Tata bahasa hanya diajarkan secara sekilas } \\
\text { saja, misalkan pembelajaran tentang مفعول بهول به garu hanya menunjukkan kepada kata atau } \\
\text { galimat yang berposisi sebagai } \\
\text { kalim kalimat. }\end{array}$ \\
\hline 5. & $\begin{array}{l}\text { Pembelajaran } \\
\text { dilakukan melalui } \\
\text { pemodelan (modeling) } \\
\text { dan praktek (practice) }\end{array}$ & $\begin{array}{l}\text { Di dalam kelas, guru sepenuhnya menjadi } \\
\text { model dan berkomunikasi dengan bahasa } \\
\text { target baik dalam menyampaikan materi, } \\
\text { memberikan pijakan, maupun memberikan } \\
\text { instruksi kepada siswa }\end{array}$ \\
\hline 6. & $\begin{array}{l}\text { Pembelajaran kosa } \\
\text { kata diajarkan melalui } \\
\text { demonstrasi, objek, } \\
\text { dan gambar; kosakata } \\
\text { abstrak diajarkan oleh } \\
\text { asosiasi ide }\end{array}$ & $\begin{array}{l}\text { Guru selalu memberikan clue sebelum } \\
\text { menjawab pertanyaan yang diajukan oleh } \\
\text { siswa terutama mengenai arti kosa kata } \\
\text { bahasa Arab dan kadang menuliskan dan } \\
\text { mendemonstrasikan kosa kata tersebut di } \\
\text { depan kelas }\end{array}$ \\
\hline 7. & $\begin{array}{l}\text { Kemahiran difokuskan } \\
\text { pada kemahiran } \\
\text { berbicara (speaking) } \\
\text { dan mendengarkan } \\
\text { (listening) }\end{array}$ & $\begin{array}{l}\text { Guru dan siswa satu sama lain berusaha } \\
\text { untuk bertanya dan berdiskusi dengan } \\
\text { menggunakan bahasa Arab }\end{array}$ \\
\hline 8. & $\begin{array}{l}\text { Pembelajaran ucapan } \\
\text { dan tata bahasa } \\
\text { ditekankan secara tepat }\end{array}$ & $\begin{array}{l}\text { Guru memberikan contoh bagaimana } \\
\text { membedakan pelafalan huruf (b) dan (ت) } \\
\text { dalam bahasa Arab disertai contoh dan } \\
\text { menuliskannya di papan tulis }\end{array}$ \\
\hline
\end{tabular}

2. Perbandingan Kualitatif Antara Karakteristik Direct Method dengan Pembelajaran Bahasa Arab di SMA Future Gate Kota Bekasi

\begin{tabular}{|c|c|c|}
\hline No. & $\begin{array}{l}\text { Karakteristik Direct } \\
\text { Method }\end{array}$ & $\begin{array}{l}\text { Pembelajaran Bahasa Arab di SMA } \\
\text { Future Gate }\end{array}$ \\
\hline 1. & $\begin{array}{l}\text { Materi pelajaran terdiri } \\
\text { dari kata-kata dan } \\
\text { struktur kalimat yang } \\
\text { banyak digunakan } \\
\text { sehari-hari }\end{array}$ & 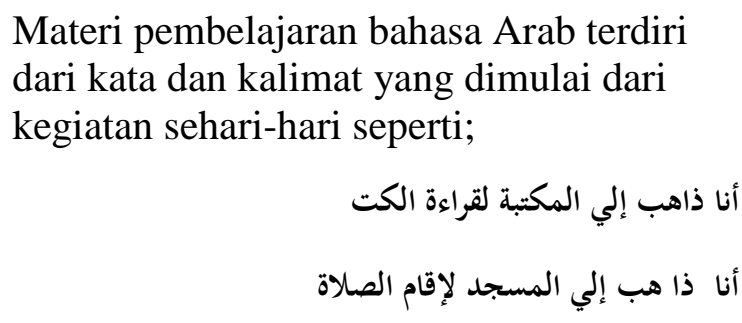 \\
\hline 2. & $\begin{array}{l}\text { Gramatika diajarkan } \\
\text { dengan melalui situasi } \\
\text { dan dilakukan secara } \\
\text { lisan bukan dengan }\end{array}$ & $\begin{array}{l}\text { Pembelajaran tentang إسم الاشارة dilakukan } \\
\text { dengan melafalkan contoh-contoh kalimat } \\
\text { yang terdapat إسم الإشارةdi dalamnya seperti; }\end{array}$ \\
\hline
\end{tabular}




\begin{tabular}{|c|c|c|}
\hline & $\begin{array}{l}\text { cara menghafalkan } \\
\text { aturan-aturan } \\
\text { gramatika }\end{array}$ & 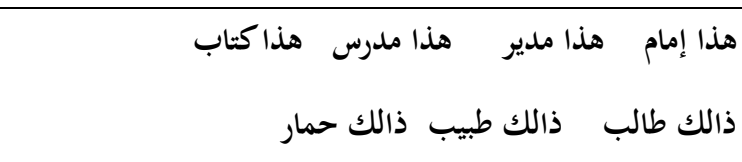 \\
\hline 3. & $\begin{array}{l}\text { Arti yang konkrit } \\
\text { diajarkan dengan } \\
\text { menggunakan benda- } \\
\text { benda, sedangkan arti } \\
\text { yang abstrak melalui } \\
\text { asosiasi }\end{array}$ & $\begin{array}{l}\text { Guru menunjukkan benda yang terdapat di } \\
\text { dalam kelas untuk benda-benda konkrit } \\
\text { seperti; سبورة, خريطة, مكتب, مقعد. } \\
\text { Sedangkan untuk arti abstrak guru } \\
\text { memberikan clue kepada siswa seperti; بارد, الباب مفتوح } \\
\text { بالنافذة مغلقة. }\end{array}$ \\
\hline 4. & $\begin{array}{l}\text { Banyak latihan-latihan } \\
\text { mendengarkan dan } \\
\text { menirukan dengan } \\
\text { tujuan agar dapat } \\
\text { dicapai penguasaan } \\
\text { bahasa secara otomatis }\end{array}$ & 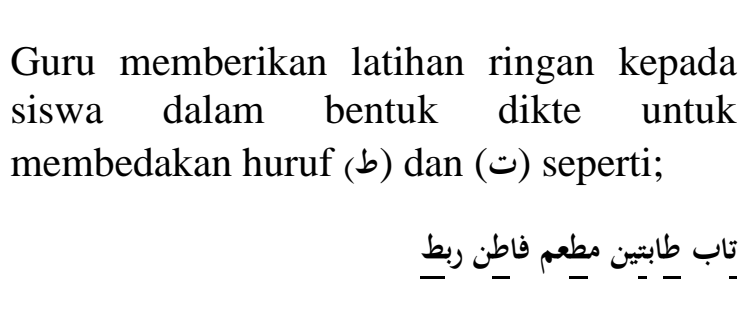 \\
\hline 5. & $\begin{array}{l}\text { Aktivitas belajar } \\
\text { banyak dilakukan di } \\
\text { dalam kelas }\end{array}$ & $\begin{array}{l}\text { Pembelajaran full inside the class dari awal } \\
\text { sampai dengan akhir pembelajaran }\end{array}$ \\
\hline 6. & $\begin{array}{l}\text { Bacaan mula-mula } \\
\text { diberikan secara lisan }\end{array}$ & $\begin{array}{l}\text { Pembelajaran dimulai dengan قراءة (bacaan) } \\
\text { atau حوار (percakapan) sederhana antara } \\
\text { guru dan murid }\end{array}$ \\
\hline 7. & $\begin{array}{l}\text { Sejak permulaan murid } \\
\text { dilatih untuk "berfikir } \\
\text { dalam bahasa asing" }\end{array}$ & $\begin{array}{l}\text { Guru selalu memberikan pijakan, perintah, } \\
\text { dan instruksi dalam bahasa Arab, } \\
\text { penggunaan bahasa Indonesia } \\
\text { diminimalisir, dan hanya beberapa kosa } \\
\text { kata saja guru mengucapkan kata atau } \\
\text { kalimat dalam bahasa Indonesia }\end{array}$ \\
\hline
\end{tabular}

3. Perbandingan Kualitatif Antara Model Penyajian Materi Direct Method dengan Pembelajaran Bahasa Arab di SMA Future Gate Kota Bekasi

\begin{tabular}{|c|l|l|}
\hline No. & $\begin{array}{c}\text { Model Penyajian } \\
\text { Materi Direct Method }\end{array}$ & \multicolumn{1}{c|}{ Pembelajaran di SMA Future Gate } \\
\hline 1. & $\begin{array}{l}\text { Reading Aloud } \\
\text { (membaca nyaring) }\end{array}$ & $\begin{array}{l}\text { Setiap siswa diwajibkan membaca satu } \\
\text { atau beberapa kalimat dengan jelas, } \\
\text { misalkan; }\end{array}$ \\
\hline
\end{tabular}




\begin{tabular}{|c|c|c|}
\hline 2. & $\begin{array}{l}\text { Question and Answer } \\
\text { Exercise (latihan } \\
\text { tanya jawab) }\end{array}$ & 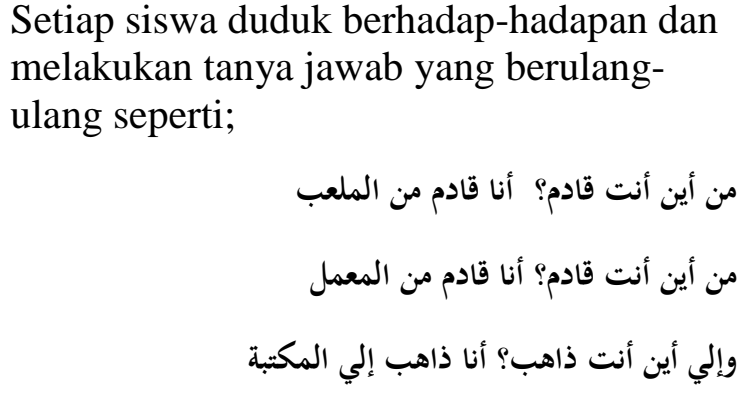 \\
\hline 3. & $\begin{array}{l}\text { Getting Students to } \\
\text { Self-Correct(siswa } \\
\text { mengoreksi diri } \\
\text { sendiri) }\end{array}$ & 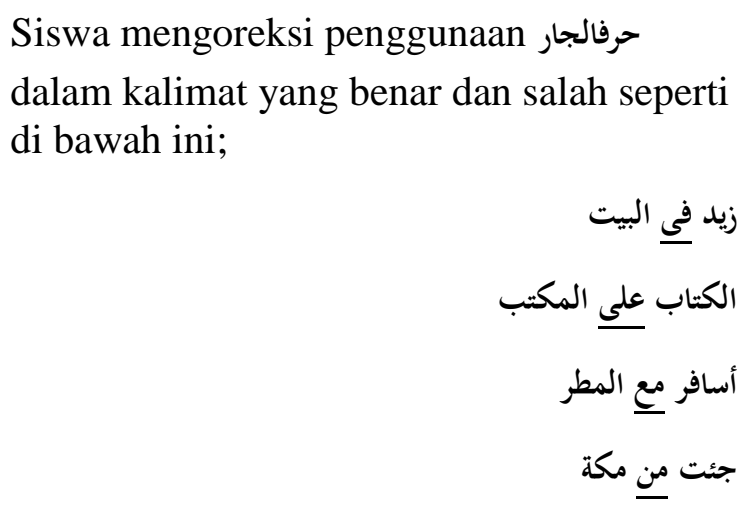 \\
\hline 4. & $\begin{array}{l}\text { Conversation Practice } \\
\text { (mempraktekkan } \\
\text { percakapan) }\end{array}$ & 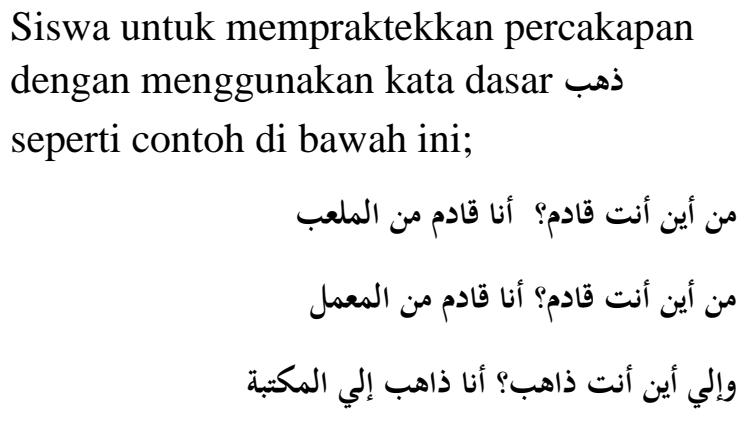 \\
\hline 5. & $\begin{array}{l}\text { Fill in the blank } \\
\text { exercise (latihan isian) }\end{array}$ & 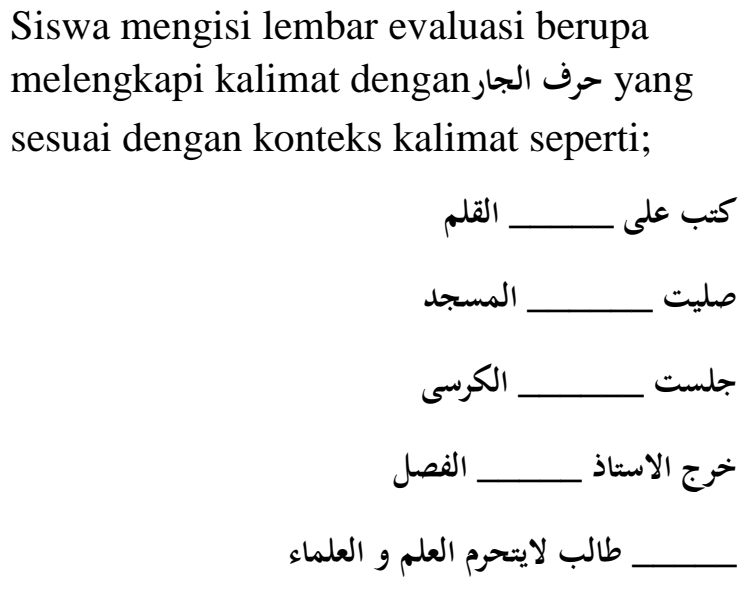 \\
\hline 6. & Dictation (dikte) & $\begin{array}{l}\text { Guru memberikan dikte untuk mengetahui } \\
\text { kemampuan siswa tentang جملة seperti; } \\
\text { المسجد كبير }\end{array}$ \\
\hline
\end{tabular}




\begin{tabular}{|c|c|c|}
\hline & & الحصل نظيف \\
\hline 7. & $\begin{array}{l}\text { Map Drawing } \\
\text { (menggambar peta) }\end{array}$ & $\begin{array}{l}\text { Guru memberikan tugas dalam bentuk } \\
\text { fortofolio kepada siswa }\end{array}$ \\
\hline 8. & $\begin{array}{l}\text { Paragraph Writing } \\
\text { (menulis paragraf) }\end{array}$ & $\begin{array}{l}\text { جملة Siswa menulis kalimat dalam bentuk } \\
\text { اسمية }\end{array}$ \\
\hline
\end{tabular}

Berdasarkan perbandingan kualitatif di atas, maka dapat disimpulkan bahwa direct method dalam pembelajaran bahasa Arab di SMA Future Gate Kota Bekasi diimplementasikan secara konsisten, masif, dan berkesinambungan. Implementasi direct method tersebut cenderung menciptakan suasana pembelajaran yang tertib dan mendorong semua siswa untuk berpartisipasi aktif dalam pembelajaran bahasa Arab.

Disini kita juga melihat peran guru bahasa Arab yang memberikan perhatian yang seimbang untuk semua siswa dalam pembelajaran di kelas, realitas tersebut diindikasikan dengan keterlibatan guru dalam mengoreksi tugas siswa satu persatu, memberikan hak yang sama kepada semua siswa untuk mengajukan pertanyaan mengenai materi pembelajaran yang belum dipahami, serta secara konsisten menggunakan bahasa Arab.

\section{Problematika Pembelajaran Bahasa Arab Berbasis Direct Method}

Keberhasilan pembelajaran bahasa Arab ditentukan oleh banyak faktor, diantaranya adalah sekolah, guru, siswa, sarana dan prasarana serta lingkungan. Selain sebagai faktor pendukung keberhasilan, faktor ini juga dapat menjadi faktor penghambat dalam pembelajaran apabila belum mampu melaksanakan tugasnya dengan maksimal.

Begitu pula dengan SMA Future Gate Kota Bekasi, meskipun telah memiliki rancangan ideal, namun masih banyak kendala dan hambatan yang menjadi problematika dalam pembelajaran bahasa Arab sekolah tersebut. Dari hasil observasi pembelajaran dan wawancara dengan kepala sekolah, guru bahasa Arab serta sebagian siswa SMA Future Gate Kota Bekasi, diketahui problematika 
pembelajaran bahasa Arab di SMA Future Gate Kota Bekasi adalah sebagai berikut;

1. Latar belakang pendidikan Siswa SMA Future Gate berasal dari yang sekolah yang beraneka ragam (SMP, MTs, dan Pesantren), ada yang pernah belajar bahasa Arab pada jenjang sebelumnya, ada yang belum pernah sama sekali belajar bahasa Arab. Realitas ini mensyaratkan guru untuk berkerja keras, agar murid yang memiliki kemampuan bahasa Arab yang sama pada jenjang berikutnya.

2. Latar belakang orang tua Siswa SMA Future Gate juga cukup beragam, ada orang tua yang tergolong agamis, namun ada juga yang tidak terlalu agamis, dikatakan agamis karena orang tua sangat memegang kuat prinsip-prinsip syar'i seperti ketaatan dalam menjalankan ibadah, cara berpakaian, dan lain sebagainya. Realitas ini menjadi tugas berat bagi sekolah untuk mengedukasi orang tua, memberikan pemahaman bahwa faktor keberhasilan pembelajaran siswa dibutuhkan kerjasama yang baik antara orang tua dan guru.

3. Minimnya jam belajar bahasa Arab untuk kelas IPA dan IPS yang hanya memiliki alokasi waktu 2 jam/pekan menjadi salah satu penyebab pembelajaran bahasa Arab kurang diminati siswa. Selain itu, bahasa Arab lebih cenderung dianggap sebagai mata pelajaran pelengkap saja, dan persepsi tentang "bahasa arab itu sulit".

4. Siswa SMA Future Gate terbagi ke dalam 2 kelompok program, yaitu Fullday School Program dan Boarding School Program. Siswa yang mengikuti Fullday School Program, hanya memiliki beban belajar sampai dengan jam pelajaran selesai atau sore hari, mereka tidak memiliki beban tambahan dan tidak mendapatkan tambahan pembelajaran di malam hari.

Sedangkan siswa yang mengikuti Boarding School Program, mereka memiliki beban yang sama dengan siswa yang mengikuti Fullday School Program sampai dengan sore hari, mereka masih memiliki beban menjadi siswa program boarding di malam hari.

Program boarding ini memang dirancang untuk menunjang program fullday terutama yang berkaitan dengan penguasaan kemampuan bahasa Asing (Arab dan 
Inggris, program Alquran (Tahsin dan Tahfidz), dan pemahaman keislaman lainnya (Tafsir, Hadits, Fiqih, Aqidah, dan Ibadah).

Disini kita melihat bahwa terdapat perbedaan fasilitas dan beban pembelajaran antara siswa yang mengikuti Fullday School Program dan Boarding School Program, siswa yang mengikuti program boarding memiliki waktu dan kesempatan yang banyak, pengawasan yang masif dan berkesinambungan dalam meningkatkan kualitas keterampilan bahasa Arabnya.

Berpijak dari problematika di atas, pihak sekolah kemudian melakukan langkah-langkah strategis guna meminimalisir problematika pembelajaran bahasa Arab berbasis direct method di SMA Future Gate tersebut, antara lain dengan cara;

1. Melakukan pendampingan khusus terhadap siswa yang belum memiliki basic bahasa Arab agar mereka mampu mengejar ketertinggalan dalam mengikuti pembelajaran bahasa Arab di kelas.

2. Memberikan pemahaman kepada orang tua agar memperkuat sinergitas antara orang tua dan guru terkait dengan pola asuh di rumah agar sejalan dengan pola belajar siswa di sekolah.

3. Melakukan rapat khusus tentang rencana penambahan jam pelajaran bahasa Arab dan atau mata pelajaran penunjang lainnya agar pembelajaran bahasa Arab berbasis direct method dapat ditingkatkan.

5. Melakukan rapat khusus tentang rencana penambahan kuota siswa yang mengikuti Boarding School Program terutama mereka yang berkeinginan melanjutkan studi ke LIPIA dan Timur Tengah.

\section{Penutup}

Berpijak dari hasil analisis dan pembahasan pada bab sebelumnya, maka dapat disimpulkan bahwa;

1. Alasan utama digunakannya direct method dalam pembelajaran bahasa Arab di SMA Future Gate Kota Bekasi dilatarbelakangi oleh keinginan kuat dari stakeholders SMA Future Gate Kota Bekasi yang menginginkan lulusannya dapat menempuh studi di dalam negeri (LIPIA) dan luar negeri (Mesir, Madinah, dll). 
2. Berdasarkan perbandingan kualitatif antara prinsip, karakteristik, dan model penyajian materi direct method dengan pembelajaran bahasa Arab berbasis direct method di SMA Future Gate Kota Bekasi, terdapat banyak kesamaan dimana metode tersebut diimplementasikan secara konsisten, masif, dan berkesinambungan.

3. Problematika pembelajaran bahasa Arab di SMA Future Gate terdiri dari; pertama, Problematika sistem (systemic problem) yang terdiri dari beberapa masalah seperti; minimnya jam pelajaran bahasa Arab khususnya untuk kelas IPA dan IPS, terpolarisasinya siswa ke dalam 2 kelompok, yaitu Fullday School Program dan Boarding School Program, dimana siswa boarding lebih banyak kesempatan menerima materi bahasa Arab karena ditunjang oleh program boarding dibanding dengan siswa fullday. Kedua, Problematika objek (objective problem) yang terdiri dari beberapa masalah sebagai berikut; perbedaan latar belakang pendidikan siswa, perbedaan latar belakang orang tua antara yang agamis dan tidak terlalu agamis (moderat). Siswa yang memiliki latar belakang pendidikan berbasis agama dan didorong oleh keinginan orang tua yang cukup agamis cenderung memiliki minat yang tinggi terhadap bahasa Arab dibanding dengan siswa yang berlatar belakang umum dan tidak ada dorongan kuat dari orang tua. 


\section{Pustaka Acuan}

Abdul Chaer, Psikolinguistik; Kajian Teoretik, Jakarta; Rineka Cipta, 2003.

Abd al-Rahman bin Ibrahim al-Fauzan, dkk, Durus al-Daurat al-tadribiyyah li Mu'alimi al-Lughah al-'Arabiah li Ghairi al-Nathiqin biha (al-Janib alNadhar), Masyru' al-'Arabiyyah li al-Jami'. 1428 H.

A. Syukur Ghazali, Pembelajaran Keterampilan Berbahasa; Dengan Pendekatan Komunikatif-Interaktif, (Bandung: Aditama, 2010), hlm. 94.

Abdullah Syukri Zarkasyi, Manajemen Pesantren; Pengalaman Pondok Modern Gontor, Ponorogo: Trimurti Press, 2005.

Dianne Larsen-Freeman, Techniques and Principles in Language Teaching, London: Oxford University Press, 2000.

H. Douglas Brown, Teaching by Principles: An Interactive Approach to Language Pedagogy, San Francisco: San Francisco State University, 1994.

,Principles of Language Learning and Teaching, San Francisco: San Francisco State University Press, 2000.

Henry Guntur Tarigan, Metodologi Pengajaran Bahasa 1, Cet. Ke-10, Bandung: Penerbit Angkasa, 1991.

Penguasaan Kedwibahasaan, Edisi Revisi, Bandung: Penerbit Angkasa, 2009.

J. C. Richard, The Language Teaching Matrix, Cambridge: Cambridge University Press, 1990.

Rodgers, Approaches and Methods in Language Teaching;A Description and Analysis, Cambridge: Cambridge University Press, 1997.

Lexy Moleong, Metode Penelitian Kualitatif, Bandung: Remaja Rosda Karya, 1999.

Mahmud Kamil al-Naqoh, Ta'lim al-Lughah al-'Arobiyah Li al-Natiqin bilughatin Ukhra; Asasuhu, Madakhiluhu, Turuq Tadrisuhu (bab tharaiq ta'lim al-lughah), Mekkah: Ummul Quro, 1980.

Matthew B. Miles dan A. Michael Huberman, Analisis Data Kualitatif, terj.Tjetjep Rohendi Rohidi, Jakarta; UI Press, 1992.

Muljanto Sumardi, Pengajaran Bahasa Asing; Sebuah Tinjauan Dari Segi Metodologi, Jakarta: Bulan Bintang, 1974.

Naif Harama \& Ali Hajaja, Al-Lughah al-Ajanabiyat, Ta'limuha wa Ta'allumuha, Kuwait: 'Alam al-Ma'rifah, 1988.

Nana Syaodih Sukmadinata, Metode Penelitian Pendidikan, Bandung: Rosda, 2009.

Noeng Muhajir, Metode Penelitian Kualitatif, Yogyalarta: Rake Sarasin, 1996.

Sembodo Ardi Widodo, Model-model Pembelajaran Bahasa Arab, dalam Jurnal Al-'Arabiyah No. 2 Vol. 2, Januari 2006. 
Syamsuddin AR dan Vismaia S. Damaianti, Metodologi Penelitian Pendidikan Bahasa, Bandung: Rosda, 2006.

http://www.englishraven.com/methodology.html, English Language Teaching Methodology, dalam Bahan ajar Mata Kuliah Pendekatan dan Metodologi Pembelajaran Bahasa Arab. 